http://jurnal.bhmm.ac.id/index.php/jpkm/index

Corresponding Author.

email address : nurmandhani@gmail.com

Ririn Nurmandhani

Received : 24 Juli 2020

Revised : 9 Agustus 2020

Accepted : 3 September 2020

\title{
Hubungan Gaya Hidup dengan Kejadian Hipertensi Di Wilayah Kerja Puskesmas Geneng, Ngawi Ririn Nurmandhani ${ }^{1}$
}

\author{
${ }^{1 *}$ Universitas Dian Nuswantoro \\ nurmandhani@gmail.com
}

\begin{abstract}
ABSTRAK
Penyakit Hipertensi sangat di pengaruhi oleh gaya hidup sehari-hari. Hipertensi atau tekanan darah tinggi adalah peningkatan tekanan darah sistolik lebih dari $140 \mathrm{mmHg}$ dan tekanan darah diastolik lebih dari $90 \mathrm{mmHg}$. Hipertensi juga sering disebut dengan pembunuh diam-diam (the silent killer) karena seringkali orang yang menderita hipertensi selama bertahun-tahun tidak merasakan suatu gangguan atau gejala. Data penderita hipertensi di Ngawi, berdasarkan data Dinas Kesehatan Kabupaten. Ngawi tahun 2016 sebanyak 10.042 orang penderita, kemudian pada tahun 2018 sebanyak 10.302 orang penderita. Angka prevalensi hipertensi diperkirakan akan terus meningkat, mengingat gaya hidup yang serba mudah, usia seseorang meningkat, kemiskinan, dan akses pelayanan kesehatan yang kurang memuaskan. Tujuan penelitian ini adalah untuk mengetahui hubungan antara gaya hidup dengan kejadian hipertensi di Wilayah Kerja Puskesmas Geneng.

Jenis penelitian ini adalah suatu penelitian Kuantitatif dengan desain studi Cross Sectional. Pengambilan sampel dilakukan dengan teknik Purposive Sampling dengan sampel 69 orang penderita hipertensi. Uji statistik menggunakan Korelasi Spearman dengan kemaknaan $\alpha<0,05$.

Hasil penelitian menunjukkan bahwa ada hubungan antara gaya hidup dengan kejadian hipertensi dengan nilai signifikan $(p)=0,000$ dimana $\leq \alpha=0,05$ dengan nilai korelasi $r=0,787$ dengan demikian maka dapat dikatakan ada hubungan yang bermakna antara gaya hidup dengan kejadian hipertensi di Puskesmas Geneng.

Berdasarkan hasil penelitian tersebut diketahui bahwa ada hubungan antara gaya hidup dengan kejadian hipertensi. Disarankan bagi responden atau masyarakat di Puskesmas Geneng agar meningkatkangaya hidup yang sehat dengan cara meningkatkan pola hidup bersih dan sehat serta menghindari hal-hal yang dapat menimbulkkan penyakit hipertensi seperti mengkomsumsi makanan asin dan awetan, berlemak dan jeroan, tidak mengkomsumsi minuman beralkohol dan berkafein, sering berolahraga, tidak merokok dan tidak stress.
\end{abstract}

Kata Kunci : Gaya Hidup, Kejadian Hipertensi

ODI : 10.47575/jpkm.vli2.I96 | VQL.INQ.22020 | ISSN: EISSN : 


\begin{abstract}
Hypertension is greatly influenced by daily lifestyle. Hypertension or high blood pressure is an increase in systolic blood pressure of more than $140 \mathrm{mmHg}$ and diastolic blood pressure of more than $90 \mathrm{mmHg}$. Hypertension is also often called the silent killer (the silent killer) because often people who suffer from hypertension for years do not feel any disturbances or symptoms. Data on hypertension sufferers in Ngawi, based on data from the District Health Office. Ngawi in 2016 there were 10,042 sufferers, then in 2018 there were 10,302 sufferers. The prevalence rate of hypertension is estimated to continue to increase, given the easy lifestyle, increasing age, poverty, and unsatisfactory access to health services. The purpose of this study was to determine the relationship between lifestyle and the incidence of hypertension in the Geneng Public Health Center.

This type of research is a quantitative study with a cross sectional study design. Sampling was done by purposive sampling technique with a sample of 69 people with hypertension. The statistical test used the Spearman Correlation with a significance of $\alpha<0.05$.

The results showed that there is a relationship between lifestyle and the incidence of hypertension with a significant value $(p)=0,000$ where $\leq \alpha=0.05$ with a correlation value $r=0.787$, thus it can be said that there is a significant relationship between lifestyle and the incidence of hypertension. at Puskesmas Geneng.

Based on the results of this study, it is known that there is a relationship between lifestyle and the incidence of hypertension. It is recommended for respondents or the community at Puskesmas Geneng to increase a healthy lifestyle by increasing a clean and healthy lifestyle and avoiding things that can cause hypertension, such as consuming salty and preserved foods, fatty and innards, not consuming alcoholic and caffeinated drinks, frequently. exercise, don't smoke and don't stress.
\end{abstract}

Keywords : Lifestyle, Incidence of Hypertension

\title{
PENDAHULUAN
}

Hipertensi atau tekanan darah tinggi adalah peningkatan tekanan darah sistolik lebih dari 140 $\mathrm{mmHg}$ dan tekanan darah diastolik lebih dari $90 \mathrm{mmHg}$ (Kemenkes RI, 2016). Hipertensi sering disebut sebagai pembunuh diam-diam (the silent killer of death) karena seringkali penderita hipertensi bertahun-tahun tanpa merasakan sesuatu gangguan atau gejala (Ainun, 2016). Hipertensi kini terus menjadi masalah global karena prevalensinya yang terus meningkat sejalan perilaku gaya hidup kurang baik seperti obesitas, merokok, penggunan alkohol, stress psikososial, dan kurangnya aktivitas (WHO,2013).

Angka prevalensi hipertensi diperkirakan akan terus meningkat, mengingat gaya hidup yang serba mudah, usia seseorang meningkat, kemiskinan, dan akses pelayanan kesehatan yang kurang memuaskan. Apabila angka kematian, kesakitan dan kecacatan ini terus meningkat maka akan berpengaruh terhadap produktivitas kerja dan meningkatnya biaya pengobatan (WHO, 2013). Laporan statistik Kesehatan Dunia 2012 menyebutkan bahwa satu dari tiga orang dewasa diseluruh dunia menderita tekanan darah tinggi. Suatu kondisi yang merupakan penyebab kematian sebagian besar yang disebabkan oleh stroke dan serangan jantung (Kemenkes, 2013).

Terdapat beberapa faktor risiko yang mempengaruhi kejadian hipertensi. Faktor risiko ini diklasifikasi menjadi faktor risiko yang tidak dapat diubah dan faktor risiko yang dapat diubah. Faktor risiko yang tidak dapat diubah adalah riwayat keluarga dengan hipertensi, umur, jenis kelamin dan etnis. Faktor risiko yang dapat diubah adalah stress, obesitas, kebiasaan merokok, kebiasaan konsumsi alkohol, aktivitas fisik, kebiasaan konsumsi lemak dan garam berlebihan (Bustan, 2007).

Penyakit hipertensi sering terjadi karena pola gaya hidup, pola makan yang tidak sehat dan jarang melakukan kontrol tekanan darah, tidak patuh dalam minum obat anti-hipertensi, mengkonsumsi makanan siap saji (fast food) yang mengandung kadar lemak tinggi, kebiasaan merokok, konsumsi minuman beralkohol, kurang olahraga, kerja berlebihan dan stres (Januar, 2016).Perilaku gaya hidup merupakan kebiasaan yang dilakukan penderita hipertensi untuk menghabiskan waktu dalam kehidupan sehari-hari. Yang termasuk dalam gaya hidup adalahpola makanan, aktifitas fisik,merokok dan stres. 
Jenis makanan yang menyebabkan hipertensi yaitu makanan yang siap saji yang mengandung pengawet, kadar garam yang terlalu tinggi dalam makanan, kelebihan konsumsi lemak (Susilo, 2011).Mengonsumsi makanan yang tidak sehat seperti jeroan, keripik asin, otak-otak,makanan dan minuman yang didalam kaleng (sarden, kornet). Makanan di atas tidak sesuai dengan kalori yang dibutuhkan dan mengandung banyakbahan pengawet (Muhammadun, 2010).

Adapun cara penanganan untuk menurunkan hipertensi adalah dimulai dengan meningkatkan kesadaran masyarakat dan perubahan gaya hidup ke arah yang lebih sehat. Kegiatan ini terbukti dapat membantu menurunkan hipertensi, oleh karena itu penderita hipertensi dianjurkan untuk diet sehat dengan cara makan cukup sayur-buah, rendah garam dan lemak, rajin melakukan aktifitas, mengurangi stres dan tidak merokok (Tjandra, 2012).

\section{METODE PENELITIAN}

Jenis penelitian ini adalah suatu penelitian korelasi dengan desain Cross Sectional. Cross sectional adalah jenis penelitian yang menekankan waktu pengukuran/observasi data variabel independen dan dependen hanya pada satu kali pada satu saat (Nursalam, 2016). Bertujuan untuk memperoleh prevalensi atau efek suatu fenomena atau variabel dependen dihubungkan dengan penyebab atau variable independen (Siswanto, 2013).

Penelitian dilaksanakan selama satu bulan yaitu bulan Mei 2019 s/d Bulan Juni 2019. Rancangan waktu penelitian mulai dari penyusunan proposal sampai dengan penyusunan laporan skripsi. Penelitian dilakukan di Puskesmas Geneng Kecamatan Geneng Kabupaten Ngawi.

Populasi dalam penelitian ini yaitu semua penderita hipertensi yang berkunjung/berobat di Puskesmas Geneng. Besar sampel pada penelitian ini sebanyak 69 responden. Inklusi dari penelitian ini yaitu pasien yang terdaftar sebagai penderita hipertensi di Puskesmas Geneng, pasien yang berusia lebih dari 35 tahun, dan pasien yang bersedia menjadi responden. Teknik pengambilan sampel dilakukan dengan teknik purposive sampling yaitu cara pengambilan sampel untuk tujuan tertentu, dimana teknik penetapan sampel dengan cara memilih sampel diantara populasi sesuai yang dikehendaki oleh peneliti sehingga sampel tersebut dapat mewakili karakteristik populasi yang telah dikenal sebelumnya (Nursalam, 2013).

Instrumen penelitian ini menggunakan kuesioner yang diambil dari Aisyiyah (2009), dengan sub variabel aktivitas fisik, kebiasaan makan, kebiasaan minum alkohol, kebiasaan minum kafein, kebiasaan merokok, dan stres.

Untuk menentukan skor atau nilai untuk setiap item pertanyaan dan tentukan nilai terendah dan tertinggi. Tahapan ini dilakukan setelah ditentukan kode jawaban atau hasil observasi dapat diberikan skor (Nasehudin dkk, 2012).

Analisa data yang dikumpulkan diolah dengan menggunakan bantuan komputer program SPSS ( Statistical Program for Social Science). Untuk mengetahui normalitas data perlu dilakukan uji normalitas dengan menggunakan nilai Kolmogorov-smirnov. Syarat digunakannya uji Kolmogorovsmirnov jika sampel lebih dari $>50$ responden, data tunggal/belum di kelompokkan pada tabel distribusi frekuensi. Dasar pengambilan keputusan dalam uji normalitas Kolmogorov-smirnov. Jika nilai signifikansi (Sig.) lebih besar dari 0,05 maka data penelitian berdistribusi normal. Jika nilai signifikansi (Sig.) lebih kecil dari 0,05 maka data penelitian tidak berdistribusi normal.

Kemudian data diolah menggunakan uji statistik Spearman Rho untuk mengetahui hubungan antara 2 variabel, dengan tingkat kemaknaan $(\alpha): 0,05$, jika nilai signifikan (p) lebih kecil dari $\alpha$ maka dikatakan penelitian diterima, dan jika nilai signifikan hasil (p) lebih besar dari $\alpha$ maka dikatakan hasil penelitian ditolak. 


\section{HASIL DAN PEMBAHASAN}

\section{Data Umum Responden}

Tabel 1.

Distribusi Frekuensi Responden Berdasarkan Jenis Kelamin

di Puskesmas Geneng Kecamatan Geneng Kabupaten Ngawi Tahun 2019

\begin{tabular}{|c|c|c|}
\hline $\begin{array}{c}\text { Jenis } \\
\text { Kelamin }\end{array}$ & Frekuensi & $\begin{array}{c}\text { Presentase } \\
(\mathbf{\%})\end{array}$ \\
\hline Laki-Laki & 13 & $18,8 \%$ \\
\hline Perempuan & 56 & $81,2 \%$ \\
\hline Jumlah & 69 & $100 \%$ \\
\hline
\end{tabular}

Sumber : Data Primer, 2019

Berdasarkan Tabel.1 menunjukkan bahwa sebagian besar responden berjenis kelamin perempuan yaitu 56 responden $(81,2 \%)$ dan yang berjenis kelamin laki-laki yaitu 13 responden $(18,8 \%)$.

Tabel 2.

Distribusi Frekuensi Responden Berdasarkan Usia di Puskesmas Geneng Kecamatan Geneng Kabupaten Ngawi Tahun 2019

\begin{tabular}{|c|c|c|}
\hline Usia & Frekuensi & Presentase (\%) \\
\hline Dewasa awal 26 - 35 tahun & 3 & $4,3 \%$ \\
\hline Dewasa akhir 36 - 45 tahun & 7 & $10,1 \%$ \\
\hline Lansia awal 46 - 55 tahun & 17 & $24,6 \%$ \\
\hline Lansia akhir 56 - 65 tahun & 23 & $33,3 \%$ \\
\hline Manula 66 - 75 tahun & 19 & $27,5 \%$ \\
\hline Jumlah & 69 & $100,0 \%$ \\
\hline
\end{tabular}

Sumber : Data Primer, 2019

Berdasarkan tabel 2 menunjukkan bahwa sebagian besar dari 69 responden berusia lansia akhir 56 - 65 tahun, yaitu sejumlah 23 responden (33,3\%). Dan sebagian kecil responden berusia dewasa awal 26-35, yaitu 3 responden $(4,3 \%)$.

Tabel 3.

Distribusi Frekuensi Responden Berdasarkan Pendidikan Terakhir di Puskesmas Geneng Kecamatan Geneng Kabupaten Ngawi Tahun 2019

\begin{tabular}{|c|c|c|}
\hline Pendidikan Terakhir & Frekuensi & $\begin{array}{c}\text { Prosentase } \\
(\mathbf{\%})\end{array}$ \\
\hline SD & 43 & $62,3 \%$ \\
\hline SLTP & 12 & $17,4 \%$ \\
\hline SLTA & 12 & $17,4 \%$ \\
\hline Sarjana & 2 & $2,9 \%$ \\
\hline Jumlah & 69 & $100 \%$ \\
\hline
\end{tabular}

Sumber : Data Primer, 2019

Berdasarkan tabel 3 menunjukkan bahwa sebagian besar responden berpendidikan terakhir SD sebanyak $43(62,3 \%)$ dan sebagian kecil responden yang berpendidikan terakhir Sarjana sebanyak 2 $(2,9 \%)$. 
Tabel 4.

Distribusi Frekuensi Responden Berdasarkan Pekerjaan

di Puskesmas Geneng Kecamatan Geneng Kabupaten Ngawi 2019

\begin{tabular}{|l|c|c|}
\hline \multicolumn{1}{|c|}{ Pekerjaan } & Frekuensi (f) & Persentase (\%) \\
\hline Pensiunan & 1 & $1,4 \%$ \\
\hline Petani & 48 & $69,6 \%$ \\
\hline $\begin{array}{l}\text { Pegawai } \\
\text { Negeri }\end{array}$ & 2 & $2,9 \%$ \\
\hline Wiraswasta & 3 & $4,3 \%$ \\
\hline $\begin{array}{l}\text { Ibu Rumah } \\
\text { Tangga }\end{array}$ & 15 & $21,7 \%$ \\
\hline \multicolumn{1}{|c|}{ Jumlah } & 69 & $100,0 \%$ \\
\hline
\end{tabular}

Sumber : Data Primer, 2019

Berdasarkan tabel 4 menunjukkan bahwa lebih sebagian besar responden bekerja sebagai petani sebanyak $48(69,6 \%)$ dan sebagian kecil responden pensiunan sebanyak 1 (1,4\%). Sedangkan responden yang bekerja sebagai pegawai negeri sebanyak 2 responden $(2,9 \%)$, responden yang bekerja wiraswasta sebanyak 3 responden $(4,3 \%)$, dan responden yang bekerja sebagai ibu rumah tangga sebanyak 15 responden $(21,7 \%)$.

Tabel 5.

Distribusi Frekuensi Responden Berdasarkan Kejadian Hipertensi di Puskesmas Geneng Kecamatan Geneng Kabupaten Ngawi Tahun 2019

\begin{tabular}{|l|c|c|}
\hline Kejadian Hipertensi & Frekuensi & Presentase (\%) \\
\hline Hipertensi Ringan & 10 & $14,5 \%$ \\
\hline Hipertensi Sedang & 46 & $66,7 \%$ \\
\hline Hipertensi Berat & 13 & $18,8 \%$ \\
\hline Jumlah & 69 & $100,0 \%$ \\
\hline
\end{tabular}

Sumber : Data Primer, 2019

Berdasarkan tabel 5 menunjukkan bahwa kejadian hipertensi di Wilayah Kerja Puskesmas Geneng mayoritas mengalami hipertensi sedang yaitu sebanyak 46 responden (66,7\%). Sedangkan responden yang mengalami hipertensi ringan sebanyak 10 responden $(14,5 \%)$ dan responden yang mengalami hipertensi berat sebanyak 13 responden $(18,8 \%)$.

Tabel 6

Distribusi Frekuensi Responden Berdasarkan Perilaku Gaya Hidup di Puskesmas Geneng Kecamatan Geneng Kabupaten Ngawi Tahun 2019

\begin{tabular}{|l|c|c|}
\hline Perilaku Gaya Hidup & Frekuensi & Presentase (\%) \\
\hline Perilaku Kurang & 55 & $79,7 \%$ \\
\hline Perilaku Cukup & 14 & $20,3 \%$ \\
\hline Perilaku Baik & 0 & $0 \%$ \\
\hline Jumlah & 69 & $100,0 \%$ \\
\hline
\end{tabular}

Sumber : Data Primer, 2019

Berdasarkan tabel 6 menunjukkan bahwa perilaku gaya hidup di Wilayah Kerja Puskesmas Geneng mayoritas mengalami perilaku gaya hidup kurang yaitu sebanyak 55 responden (79,7\%). Sedangkan responden yang mengalami perilaku gaya hidup cukup sebanyak 14 responden $(20,3 \%)$. 
Tabel 7.

Tabulasi Silang Hubungan Antara Perilaku Gaya Hidup Dengan Kejadian Hipertensi Di Puskesmas Geneng Kecamatan Geneng Kabupaten Ngawi Tahun 2019

\begin{tabular}{|c|c|c|c|c|}
\hline \multirow{2}{*}{$\begin{array}{c}\text { Perilaku Gaya } \\
\text { Hidup }\end{array}$} & \multicolumn{3}{|c|}{ Kejadian Hipertensi } & \multirow{2}{*}{ Total } \\
\hline & Ringan & Sedang & Berat & \\
\hline Kurang & $\begin{array}{c}10 \\
14,5 \%\end{array}$ & $\begin{array}{c}45 \\
65,2 \% \\
\end{array}$ & $\begin{array}{c}0 \\
0 \% \\
\end{array}$ & $\begin{array}{c}55 \\
79,7 \% \\
\end{array}$ \\
\hline Cukup & $\begin{array}{c}0 \\
0 \%\end{array}$ & $\begin{array}{c}1 \\
1,4 \%\end{array}$ & $\begin{array}{c}13 \\
18,8 \%\end{array}$ & $\begin{array}{c}14 \\
20,3 \%\end{array}$ \\
\hline Jumlah & $\begin{array}{c}10 \\
14,5 \%\end{array}$ & $\begin{array}{c}46 \\
66,7 \%\end{array}$ & $\begin{array}{c}13 \\
18,8\end{array}$ & $\begin{array}{c}69 \\
100 \%\end{array}$ \\
\hline
\end{tabular}

Sumber : Data Primer, 2019

Berdasarkan tabel 7 dijelaskan bahwa responden dengan perilaku gaya hidup kurang responden mengalami hipertensi ringan sebanyak 10 orang (14,5\%), dan yang mengalami hipertensi sedang sebanyak 45 orang $(65,2 \%)$. Responden dengan perilaku gaya hidup cukup mengalami hipertensi sedang sebanyak 1 orang $(1,4 \%)$ dan yang mengalami hipertensi berat sebanyak 13 orang $(18,8 \%)$.

Hasil uji statistik Spearman's rho dengan nilai kemaknaan $(\alpha)=0,05$ didapatkan nilai Signifikan $(p)=0$, 000 yang lebih kecil dari $\alpha=0,05$ dengan demikian maka dapat dikatakan H1 diterima dan H0 ditolak artinya ada hubungan yang bermakna antara perilaku gaya hidup dengan kejadian hipertensi di Puskesmas Geneng Kecamatan Geneng. Nilai koefisien korelasi Spearman rho (r) sebesar 0,787 menunjukkan bahwa kekuatan korelasi yaitu kuat (Data Primer, 2019).

Berdasarkan tabel 5 dijelaskan bahwa karakteristik responden yang berjumlah 69 orang hasil penelitian menunjukkan bahwa prevalensi responden yang mengalami hipertensi mayoritas hipertensi sedang. Dikatakan hipertensi sedang karena tekanan darah sistolik 160-179 mmHg dan tekanan darah diastolik 100-109 mmHg. Menurut Joint National Committee VII, seseorang dikatakan hipertensi jika tekanan darah sistoliknya $\geq 140 \mathrm{mmHg}$ dan tekanan darah diastoliknya $\geq 90 \mathrm{mmHg}$ (Kemenkes.RI, 2014).

Menurut Aisyiyah (2009), Hipertensi dapat disebabkan oleh adanya faktor-faktor yang secara alami telah ada pada seseorang. Faktor yang mempengaruhi hipertensi antara lain genetik, umur dan jenis kelamin. Hasil penelitian dari Sthefhany (2012) yang menunjukkan bahwa terdapat hubungan yang bermakna antara riwayat hipertensi, kebiasaan konsumsi lemak dan kebiasaan konsumsi natrium dengan hipertensi $(p<0,05)$. Hasil penelitian yang dilakukan oleh Sugiharto (2007) pada masyarakat di Kabupaten Karanganyar, riwayat keluarga dengan hipertensi atau keturunan terbukti sebagai faktor risiko terjadinya hipertensi. Risiko terjadinya hipertensi sebesar 4,04 kali dibandingkan orang yang orang tuanya tidak menderita hipertensi.

Berdasarkan tabel 1 dijelaskan bahwa jenis kelamin responden penderita hipertensi sebagian besar berjenis kelamin perempuan sebanyak 56 responden $(81,2 \%)$. Wanita cenderung memiliki tekanan darah yang lebih tinggi daripada laki-laki pada usia tersebut (Perry \& Potter, 2005). Wanita lebih banyak yang menderita hipertensi dibanding laki-laki, hal ini disebabkan karena terdapatnya hormon estrogen pada wanita. Menurut Cortas (2008), prevalensi terjadinya hipertensi pada laki-laki sama dengan wanita. Namun wanita terlindung dari penyakit kardiovaskular sebelum menopause. Wanita yang belum mengalami menopause dilindungi oleh hormon estrogen yang berperan dalam meningkatkan kadar HDL. Kadar kolesterol HDL yang tinggi merupakan faktor pelindung dalam mencegah terjadinya proses aterosklerosis.

Berdasarkan tabel 2 dijelaskan bahwa responden penderita hipertensi yang telah masuk lansia sebanyak 59 responden. Ditemukan kecenderungan peningkatan prevalensi menurut peningkatan usia dan biasanya pada usia $>40$ tahun, pada usia 20-40 tahun dimana tahanan perifer meningkat (Sharma, 2008). Resiko hipertensi meningkat seiring dengan bertambahnya umur, hal ini disebabkan oleh adanya perubahan struktur pada pembuluh darah besar sehingga lumen menjadi sempit dan dinding pembuluh darah menjadi lebih kaku. Sebagai akibat adalah meningkatnya tekanan darah sitolik (Muhammadun, 2010). 
Berdasarkan tabel 3 dijelaskan bahwa pendidikan responden penderita hipertensi sebagian besar berpendidikan SD sebanyak 43 responden (62,3\%). Penelitian ini sejalan dengan penelitian Yusida (2015) yang menemukan ada hubungan yang bermakna antara pendidikan dengan kejadian hipertensi dengan nilai $\mathrm{p}=0,023$ dan $\mathrm{OR}=1,721$. Hal ini juga sejalan dengan hasil Riskesdas (2007) yang menyatakan bahwa penyakit hipertensi cenderung tinggi pada pendidikan rendah dan menurun sesuai dengan peningkatan pendidikan. Hubungan ini tidak semata-mata diakibatkan perbedaan tingkat pendidikan, tetapi tingkat pendidikan berpengaruh terhadap gaya hidup sehat dengan tidak merokok, tidak minum alkohol, dan lebih sering berolahraga. Tingginya risiko terkena hipertensi pada pendidikan yang rendah, kemungkinan disebabkan karena kurangnya pengetahuan pada pasien yang berpendidikan rendah terhadap kesehatan dan sulit atau lambat menerima informasi (penyuluhan) yang diberikan oleh petugas sehingga berdampak pada perilaku/pola hidup sehat (Yuliarti, 2007 dalam Panjaitan, 2015).

Berdasarkan tabel 6 hasil penelitian ini didapatkan data bahwa perilaku gaya hidup responden mayoritas mempunyai perilaku gaya hidup yang kurang yaitu sebanyak 55 responden $(79,7 \%)$. Berdasarkan kuesioner, dikatakan perilaku gaya hidup kurang jika responden tidak melakukan aktifitas fisik, mempunyai kebiasaan makan yang tidak sehat, mengonsumsi alkohol dan kafein, mempunyai kebiasaan merokok dan stres. Dalam era modern seperti ini banyak masyarakat yang lebih memilih memakai sepeda motor dibandingkan jalan kaki, selain itu banyak yang lebih suka makan makanan yang siap saji atau siap makan dibandingkan dengan makan sayuran atau hasil makanan masakan sendiri. Sedangkan yang mempunyai perilaku gaya hidup cukup sebanyak 14 responden (20,3\%). Dikatakan perilaku gaya hidup cukup jika melakukan aktifitas fisik, mempunyai kebiasaan makan yang sehat, tidak mengonsumsi alkohol dan kafein, tidak merokok dan tidak stres.

Berdasarkan tabel 7 hasil penelitian menunjukkan bahwa ada hubungan antara perilaku gaya hidup dengan kejadian hipertensi menggunakan uji statistik korelasi Spearman rho didapatkan $\mathrm{p}$ value $(\mathrm{p}=0,000)$ lebih kecil dari nilai $\alpha(\alpha=0,05)$, maka $\mathrm{H} 1$ diterima dan $\mathrm{H} 0$ ditolak yang berarti ada hubungan antara perilaku gaya hidup dengan kejadian hipertensi. Hasil penelitian menunjukkan bahwa sebagian besar responden mempunyai perilaku gaya hidup kurang sebanyak 55 responden dengan presentase $79,7 \%$ dengan nilai koefisien sebesar 0,787 menunjukkan bahwa kekuatan korelasi yaitu kuat.

Penelitian yang dilakukan oleh Diaz (2002), yang meneliti tentang hubungan antara gaya hidup dengan hipertensi pada masyarakat didapatkan kolerasi (r) $=0,42$. Suoth (2014) mengatakan bahwa gaya hidup sangat mempengaruhi terjadinya penyakit hipertensi. Sejalan dengan pelitian Panjaitan (2015), bahwa ada hubungan gaya hidup dengan kejadian hipertensi dengan nilai koefisien (r) $=0,806$ menunjukkan korelasi yaitu sangat kuat. Penderita hipertensi yang tidak memiliki kebiasaan perilaku sehat dalam setiap hari nya akan berdampak pada kesehatanya. Semakin tinggi perilaku gaya hidup tidak sehat, semakin meningkatkan kejadian hipertensi.

Dalam kuesioner pada penelitian ini ditemukan perilaku gaya hidup kurang yang mengalami hipertensi sedang sebanyak 45 responden $(65,2 \%)$, kebanyakan masyarakat tidak memperhatikan perilaku gaya hidupnya. Jarang melakukan olahraga, ketika baru bangun kebanyakan dari mereka langsung melakukan aktifitas tanpa berolahraga sebelumnya dan pergi ke suatu tempat lebih memilih memakai sepeda motor daripada jalan kaki. Padahal dalam melakukan aktivitas fisik, otot membutuhkan energi diluar metabolisme untuk bergerak, sedangkan jantung dan paru-paru memerlukan tambahan energi untuk mengantarkan zat-zat gizi dan oksigen ke seluruh tubuh dan untuk mengeluarkan sisa-sisa dari tubuh. Jika tidak melakukan olahraga membuat aktivitas fisik menurun yang berarti makin sedikit energi yang digunakan dan makin banyak energi yang ditimbun (Ngurah, 2014). Selain itu, juga jarang mengonsumsi makan makanan yang sehat kadang mengonsumsi makanan asin dan awetan, karena makanan asin dan awetan biasanya memiliki rasa gurih (umami), sehingga dapat meningkatkan nafsu makan. Makanan asin dan makanan yang diawetkan adalah makanan dengan kadar natrium tinggi. Natrium adalah mineral yang sangat berpengaruh pada mekanisme timbulnya hipertensi (Hanafi, 2016). Kebiasaan merokok juga berpengaruh terhadap hipertensi. Rokok mengandung senyawa kimia yang sangat berbahaya, terutama nikotin dan karbon monoksida. Zat tersebut dihisap dan kemudian masuk ke dalam aliran darah. Zat tersebut dapat merusak pembuluh darah yang akan menyebabkan aterosklerosis yang meneyebabkan penyempitan pembuluh darah sehingga menyebabkan tekanan dalam dinding arteri meningkat (Depkes. 2008). 
Stres juga dapat meningkatkan tekanan darah pada banyak orang, namun tidak semua orang, dan walaupun ketegangan tidak selalu identik dengan hipertensi. Hasil penelitian ini sesuai dengan penelitian Sugiharto (2007) terdapat hubungan antara stress dengan kejadian hipertensi yaitu orang yang stress kejiwaan mengalami hipertensi. Stress meningkatkan aktivitas saraf simpatis, yang dapat meningkatkan tekanan darah secara bertahap yang berarti semakin stress seseorang akan semakin tinggi tekanan darahnya (Syavardie, 2014). Mengonsumsi kafein juga bisa menyebabkan terjadinya hipertensi. Menurut penelitian eksperimental Winkelmayer, dkk (2005) kafein akan meningkatkan konsentrasi hormon stres seperti epinefrin, norepinefrin, dan kortisol yang dapat meningkatkan tekanan darah. Beberapa peneliti menyatakan bahwa kafein dapat memblokir efek adenosine yaitu hormon yang menjaga agar pembuluh darah tetap lebar. Kafein juga merangsang kelenjar adrenal untuk melepas lebih banyak kartisol dan adrenalin yang dapat memicu tekanan darah menjadi meningkat (Sheps, 2005).

Dan dari analisa kuesioner ditemukan perilaku gaya hidup cukup yang mengalami hipertensi berat sebanyak 13 responden (18.8\%), kebanyakan masyarakat yang mengalami hipertensi berat tidak seimbang dengan perilaku gaya hidup yang mereka jalani. mereka melakukan aktifitas fisik, tapi mempunyai kebiasaan makan yang tidak sehat, tidak mengonsumsi alkohol, mengonsumsi kafein, merokok dan juga mengalami stres. Sehingga diperkirakan angka prevalensi hipertensi akan terus meningkat, mengingat gaya hidup yang serba mudah, usia seseorang meningkat, kemiskinan, dan akses pelayanan kesehatan yang kurang memuaskan. Apabila angka kematian, kesakitan dan kecacatan ini terus meningkat maka akan berpengaruh terhadap produktivitas kerja dan meningkatnya biaya pengobatan (WHO, 2013).

Hasil penelitian ini didukung penelitian dari Ainun (2015) dengan hasil bahwa ada hubungan gaya hidup dengan kejadian hipertensi di Makassar. Hasil penelitian ini juga didukung penelitian dari Hanafi (2016) yang mengatakan ada hubungan gaya hidup dengan kejadian hipertensi di Kecamatan Sumowono Semarang.Dengan demikian, perlu diperhatikan agar tidak berlanjut kearah komplikasi dan berujung kematian. Peningkatan tekanan darah yang berlangsung dalam jangka waktu yang lama dapat menimbulkan kerusakan pada ginjal (gagal ginjal), jantung (penyakit jantung koroner) dan otak (Kemenkes RI, 2014).

\section{KESIMPULAN}

Berdasarkan hasil penelitian yang dilakukan diketahui bahwa :

1. Sebagian besar penderita hipertensi di Wilayah Kerja Puskesmas Geneng memiliki perilaku gaya hidup yang kurang sebanyak 55 responden $(79,7 \%)$.

2. Sebagian besar penderita hipertensi di Wilayah Kerja Puskesmas Geneng mengalami hipertensi sedang sebanyak 46 responden $(66,7 \%)$.

3. Terdapat hubungan antara perilaku gaya hidup dengan kejadian hipertensi di Wilayah Kerja Puskesmas Geneng dengan nilai koefisien korelasi $\mathrm{r}=0,787$ menunjukkan bahwa kekuatan korelasi yaitu kuat.

\section{SARAN}

Diharapkan bagi masyarakat di Wilayah Kerja Puskesmas Geneng agar lebih meningkatkan pencegahan hipertensi dengan modifikasi gaya hidup dan menambah wawasan tentang hal-hal yang dapat mencegah faktor terjadinya hipertensi serta rutin mengontrol tekanan darah. 


\section{DAFTAR PUSTAKA}

Ainun, S dkk. 2015. "Hubungan Gaya Hidup dengan Kejadian Hipertensi pada Mahasiswa di Lingkup Kesehatan Universitas Hasanuddin”. Makassar: Fakultas Kesehatan Masyarakat Universitas Hasanuddin.

Aisyiyah, F. 2009. Faktor Risiko Hipertensi pada Empat Kabupaten/Kota dengan Prevalensi Hipertensi Tertinggi di Jawa dan Sumatera. Tidak Dipublikasikan. Skripsi. Bogor: Fakultas Ekologi Manusia Institut Pertanian Bogor. [serial online] http://www.ipb.or.id

Arikunto, S. 2010. Prosedur Penelitian Pendekatan Praktik. Jakarta : Rineka Cipta.

Budiharto. 2010. Pengantar Ilmu Perilaku Kesehatan dan Pendidikan Kesehatan Gigi. Jakarta : EGC.

Cortas, K. 2008. Hypertension. [serial online]. http://www.emedicine.com

Hanafi, A. 2016. "Gambaran Gaya Hidup Penderita Hipertensi di Kecamatan Sumowono Kabupaten Semarang”. Skripsi. Semarang: fakultas kedokteran Universitas Diponegoro.

Kemenkes, RI. 2016. Pusat Data Dan Informasi. Profil Kesehatan Indonesia.

Muhammadun. 2010. Hidup Bersama Hipertensi. Yogyakarta:In-Books.

Notoatmodjo. 2010. Promosi Kesehatan Teori dan Aplikasi. Jakarta: Rineka Cipta. . 2011. Pendidikan Dan Perilaku Kesehatan. Jakarta : Rineka Cipta. 2012. Metode Penelitian Kesehatan. Jakarta : Rineka Cipta.

Nursalam. 2012. Pendidikan Dalam Keperawatan. Jakarta : Salemba Medika. . 2012. Konsep dan Penerapan Metodologi Penelitian Ilmu Keperawatan: Pedoman Skripsi, Tesis dan Instrumen Penelitian Keperawatan. Jakarta : Salemba Medika.

Nursalam. 2016. Metodologi Penelitian Kualitatif dan Kuantitatif dalam Bidang Kesehatan. Yogyakarta: Nuha Medika.

Profil Kesehatan Kabupaten Ngawi. 2016.

Profil Kesehatan Kabupaten Ngawi. 2018.

Purwanto. 2011. Statistika Untuk Penelitian. Penerbit: Pustaka Belajar.

Sharma S, et al. 2008. Hypertension. [serial online] http//:www.emedicine.com

Sheps, Sheldon G. 2005. Mayo Clinic Hipertensi, Mengatasi Tekanan Darah Tinggi. Jakarta: PT Intisari Mediatama.

Sugiyono. 2011. Statistik Untuk Penelitian. Bandung : CV Alfabeta.

South, M dkk. 2014." Hubungan Gaya Hidup dengan Kejadian Hipertensi di Puskesmas Kolongan Kecamatan Kalawat Kabupaten Minahasa Utara". ejournal keperawatan, vol 7 no. 2.

Tjandra. 2012. Masalah Hipertensi di Indonesia. www.depkes.go.id.

Triyanto,E., 2014. Pelayanan Keperawatan Bagi Penderita Hipertensi Secara Terpadu. Yogyakarta : Graha Ilmu

Wawan, A Dan Dewi, M. 2010. Teori dan Pengukuran Pengetahuan, Sikap, dan Perilaku Manusia. Yogyakarta: Nuha Medika.

Winkelmauer, W. C., Stampler, M, J., \& Willett, W. C. 2005. Habitual Caffeine Intake and the risk of Hypertension in Woman. JAMA, 294 (18).

World Health Organization. 2013. A global brief on hypertension: Silent killer, global public health crisis. Geneva; WHO: Swiss 